\title{
Ecohydrological optimality in the Northeast China Transect
}

\author{
Zhentao Cong ${ }^{1,2}$, Qinshu Li ${ }^{1,2}$, Kangle Mo ${ }^{1,2}$, Lexin Zhang ${ }^{1,2}$, and Hong Shen ${ }^{1,2}$ \\ ${ }^{1}$ Department of Hydraulic Engineering, Tsinghua University, Beijing, 100084, China \\ ${ }^{2}$ State Key Laboratory of Hydroscience and Engineering, Beijing, 100084, China
}

Correspondence to: Zhentao Cong (congzht@ @tsinghua.edu.cn)

Received: 26 January 2017 - Discussion started: 27 January 2017

Revised: 9 April 2017 - Accepted: 10 April 2017 - Published: 10 May 2017

\begin{abstract}
The Northeast China Transect (NECT) is one of the International Geosphere-Biosphere Program (IGBP) terrestrial transects, where there is a significant precipitation gradient from east to west, as well as a vegetation transition of forest-grassland-desert. It is remarkable to understand vegetation distribution and dynamics under climate change in this transect. We take canopy cover $(M)$, derived from Normalized Difference Vegetation Index (NDVI), as an index to describe the properties of vegetation distribution and dynamics in the NECT. In Eagleson's ecohydrological optimality theory, the optimal canopy cover $\left(M^{*}\right)$ is determined by the trade-off between water supply depending on water balance and water demand depending on canopy transpiration. We apply Eagleson's ecohydrological optimality method in the NECT based on data from 2000 to 2013 to get $M^{*}$, which is compared with $M$ from NDVI to further discuss the sensitivity of $M^{*}$ to vegetation properties and climate factors. The result indicates that the average $M^{*}$ fits the actual $M$ well (for forest, $M^{*}=0.822$ while $M=0.826$; for grassland, $M^{*}=0.353$ while $M=0.352$; the correlation coefficient between $M$ and $M^{*}$ is 0.81 ). Results of water balance also match the field-measured data in the references. The sensitivity analyses show that $M^{*}$ decreases with the increase of leaf area index (LAI), stem fraction and temperature, while it increases with the increase of leaf angle and precipitation amount. Eagleson's ecohydrological optimality method offers a quantitative way to understand the impacts of climate change on canopy cover and provides guidelines for ecorestoration projects.
\end{abstract}

\section{Introduction}

Transect studies play an important role in understanding the role of the terrestrial biosphere in global change (Koch et al., 1995a). The Global Change and Terrestrial Ecosystems (GCTE) project of International Geosphere-Biosphere Program (IGBP) has chosen 15 transects along with environmental or land-use gradients, aiming at understanding how these factors influence terrestrial ecosystem and the interaction between biosphere and atmosphere (Koch et al., 1995b; Canadell et al., 2002; Austin and Sala, 2002). The Northeast China Transect (NECT) was identified as one of the IGBP transects in 1993, with precipitation/moisture as the main driving climate factor (Ni and Zhang, 2000; Zhang and Zhou, 2011). Along with the moisture gradient, vegetation types vary gradually from forest in the east, to the cropland in the middle, and grassland and bare soil in the west.

Vegetation plays an important role in terrestrial ecosystems. It strongly influences the exchange of energy, substances and moisture between land and atmosphere through photosynthesis, respiration and transpiration (Graetz, 1991; Mcpherson, 2007). At the same time, the vegetation growth condition is largely affected by climate factors, such as precipitation, air temperature and greenhouse gases (Füssler and Gassmann, 2000; Lotsch et al., 2003; Liu et al., 2006).

The most common indices to describe vegetation performance include Normalized Difference Vegetation Index (NDVI) and vegetation canopy cover. NDVI is a linear combination of remotely sensed near-infrared reflectance and red reflectance. It is an index reflecting the greenness of vegetation canopy and photosynthetic activity (Dorman et al., 2013; Fontana et al., 2008; Hmimina et al., 2013). Vegetation canopy cover is defined as the fraction of total ground surface covered by vegetation. Semi-empirical relationships 
between NDVI and canopy cover were used to derive the possible arithmetic expression of canopy cover (Baret et al., 1995; Carlson and Ripley, 1997; Gutman and Ignatov, 1998; Jiang et al., 2006). With the rising attention of the climate change issue, studies on the relationship between canopy cover and climate factors have been conducted in different regions of the world (Zhou et al., 2001; Schultz and Halpert, 1993; Piao et al., 2011; Park and Sohn, 2010; Li et al., 2002; Wang et al., 2003). Nie et al. (2012) used correlation analysis to check the relationship between NDVI and climate factors in the NECT, with regression equations given for different timescales. NDVI driven by climate changes varied differently between vegetation types and seasons (Piao et al., 2006). Duan et al. (2011) illustrated that precipitation was the most important factor in affecting the temporal NDVI patterns over semi-arid and arid regions of China. Peng et al. (2012) found that more than $70 \%$ of the temporal variations in NDVI were contributed by precipitation during the growing season in typical and desert steppes in northeast China. Mao et al. (2012), however, discovered that the correlation between NDVI and temperature was higher than with precipitation over most parts of northeast China for all vegetation covers; NDVI presented a downward trend with increased temperature and remarkably decreased precipitation. Further, Yuan et al. (2015) suggested diverse responses of grasslands to precipitation intensities.

Although the statistical models have been established to describe the response of vegetation to climate factors, they cannot express the underlying mechanism of the response quantitatively. Vegetation models were developed to detect how vegetation reacts to climate change based on the biophysical and physiological processes, including plant life cycle, carbon and nitrogen cycles, but many data and parameters were required (Myoung et al., 2011). It is a big challenge to build a simplified model that can describe the mechanism of vegetation response to climate change with relatively few parameters. Fortunately, Eagleson (2002) presented a theory and method: ecohydrological optimality (Eagleson, 1978a-g, 1982; Eagleson and Tellers, 1982). In Eagleson's ecohydrological optimality theory, vegetation characteristics, such as leaf angle, leaf area index (LAI) and canopy cover, are determined by the light, energy, water and soil conditions in long-term average state. Different from the models above, Eagleson's ecohydrological optimality theory can not only explore the mechanism of canopy cover distribution, mainly from the water balance perspective but is also easy to conduct. The optimality theory provides a new way to explore the quantitative relationship between vegetation and climate factors. Despite the fact that Eagleson's work is regarded as the basis for ecohydrology and is of great importance (Hatton et al., 1997; Kerkhoff et al., 2004), limited studies have been conducted using the theory in practice (Shao et al., 2011; Mo et al., 2015), which is partly due to the limitation of longterm temporal scale, partly due to the difficulty to measure vegetation characteristics.
In Eagleson's ecohydrological optimality theory, the optimal canopy cover $\left(M^{*}\right)$ is determined by the trade-off between water supply depending on water balance and water demand depending on canopy transpiration. The NDVI data offer us a method to estimate actual canopy cover. If we can verify Eagleson's ecohydrological optimality theory by comparing the optimal canopy cover and remote sensing canopy cover, we can discuss the impacts of climate factors and vegetation properties on vegetation cover. From this framework, we can certainly provide some insights in terms of the understanding of climate change impacts on canopy cover dynamics and therefore can provide useful guidelines for ecorestoration projects, especially for the selection of vegetation species and plant density. Mo et al. (2015) applied this method in Horqin Sand, China, just for one kind of vegetation. In this study, we apply Eagleson's ecohydrological optimality method in the NECT based on data from 2000 to 2013 to get $M^{*}$ and then compare with $M$ determined by NDVI to discuss the sensitivity of $M^{*}$ to vegetation properties and climate factors.

\section{Study area and data}

\subsection{Study area}

The NECT is one of the midlatitude IGBP terrestrial transects. It ranges from 42 to $46^{\circ} \mathrm{N}$ and from 106 to $134^{\circ} \mathrm{E}$. The major change gradient is precipitation, which decreases gradually from the eastern mountainous region to the middle farmland and western steppes (Fig. 1). In the east, the annual precipitation is over $600 \mathrm{~mm} \mathrm{yr}^{-1}$; meanwhile, in the west, the annual precipitation is under $200 \mathrm{~mm} \mathrm{yr}^{-1}$. The land cover types show a significant zonal distribution from east to west: temperate evergreen coniferous-deciduous broadleaf mixed forests, deciduous broadleaf forests and woodlands in the east, shrublands and crop in the middle, grassland and bare soil in the west (Fig. 1). In this study, we just focus on the growing season from May to September. The input data and parameters include remote sensing data, meteorological data, vegetation data and soil data. The remote sensing data are the vegetation cover and LAI. The main meteorological data are length of growing season, potential evaporation, air temperature and storm duration. The main vegetation data are surface retention depth, leaf angle and stem height. The main soil data are soil porosity and hydraulic conductivities. The input values are listed in Table 1.

\subsection{Remote sensing data}

Monthly NDVI (MOD13A3), yearly land cover types (MCD12Q1) and 8-day LAI (MCD15A2) datasets derived from the Moderate-resolution Imaging Spectroradiometer (MODIS) aboard the Aqua and Terra satellites are applied. These satellite data are available on the NASA website (http://reverb.echo.nasa.gov/). 


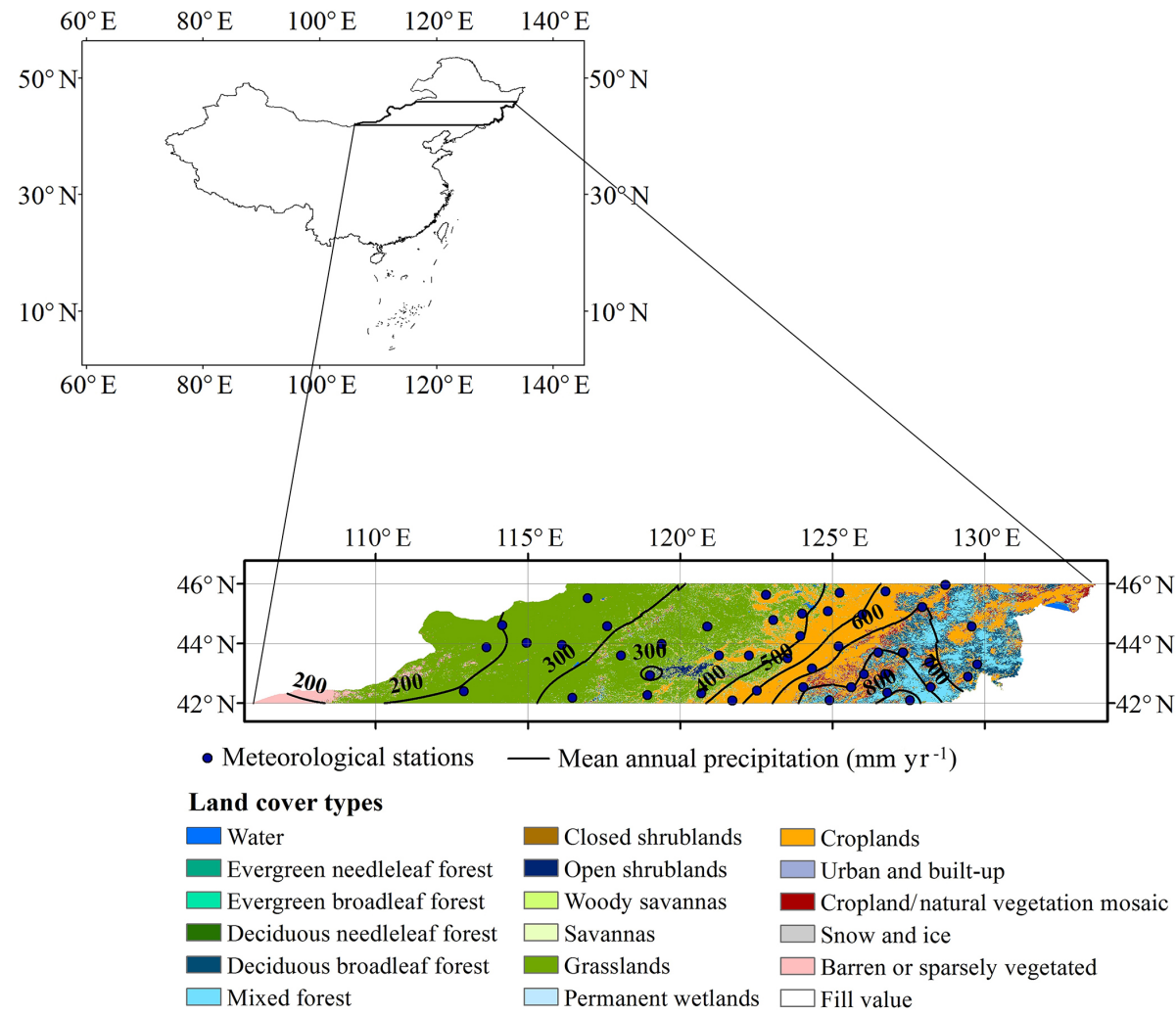

Figure 1. The geographic location, land cover, spatial distribution of precipitation and meteorological station locations of the NECT.

The spatial resolution of NDVI, land cover types and LAI dataset are $1 \mathrm{~km}, 500 \mathrm{~m}$ and $1 \mathrm{~km}$, respectively. Considering the wide longitudinal and latitudinal extends of the NECT, these remote-sensed data are resampled to be $10 \mathrm{~km} \times 10 \mathrm{~km}$. The MODIS Reprojection Tool (MRT) is applied to define coordinate systems for the images. MRT is also used to generate NDVI and LAI data for growing season of each year.

Canopy cover is defined as the fraction of total ground surface covered by vegetation (Eagleson, 2002). Usually a linear transformation of remote-sensed NDVI is used to calculate actual canopy cover $(M)$ (Gutman and Ignatov, 1998; Jiang et al., 2006):

$M=\frac{\mathrm{NDVI}-\mathrm{NDVI}_{\min }}{\mathrm{NDVI}_{\max }-\mathrm{NDVI}_{\min }}$,

in which $\mathrm{NDVI}_{\min }$ is the NDVI of barren soil and $\mathrm{NDVI}_{\max }$ is the NDVI of forests. Since the land cover of a fixed grid may be changed in different years, it was hard to define the real barren soil or the forest areas. We considered the area sensed as barren soil for every year as the barren soil area, and the $\mathrm{NDVI}_{\text {min }}$ is the spatial average of barren area NDVI. Similarly, the area sensed as forests every year is considered as the forests area, and the spatial average of forests NDVI is $\mathrm{NDVI}_{\max }$. In this study, $\mathrm{NDVI}_{\min }$ and $\mathrm{NDVI}_{\max }$ are 0.05 and 0.63 , respectively, which means the canopy cover can be regarded as 1 if the NDVI is above 0.63 and as 0 if the NDVI is below 0.05 .

\subsection{Meteorological data}

The meteorological data used in this study from 2000 to 2013 are provided by China Meteorological Data Sharing Service System (http://cdc.cma.gov.cn). The spatial distribution of the 45 meteorological stations is shown in Fig. 1. Atmospheric pressure $\left(P_{\mathrm{a}}\right)$, wind speed $\left(W_{\mathrm{nd}}\right)$, average air temperature $\left(T_{\mathrm{a}}\right)$, net radiation $\left(R_{\mathrm{n}}\right)$ (estimated by sunshine hours, $S_{\mathrm{h}}$, and air temperature; Allen, 1998), relative humidity $(\mathrm{RH})$, minimum air temperature $\left(T_{\mathrm{n}}\right)$ and maximum air temperature $\left(T_{\mathrm{m}}\right)$ are required to calculate the potential evapotranspiration by Penman-Monteith equation ( $\mathrm{Ni}$ and Zhang, 2000; Eagleson, 2002). A kriging interpolation method is applied to generate the spatial distribution of the meteorological factors and potential evapotranspiration. The spatial resolution is $10 \mathrm{~km}$ in order to be consistent with that of remote sensing data.

\section{Methodology}

Eagleson proposed three hypotheses in his ecohydrological optimality theory. He considered that climate and vegetation can influence and adapt to each other on different timescales. 
Table 1. The terminology, interpretation, units and values of inputs.

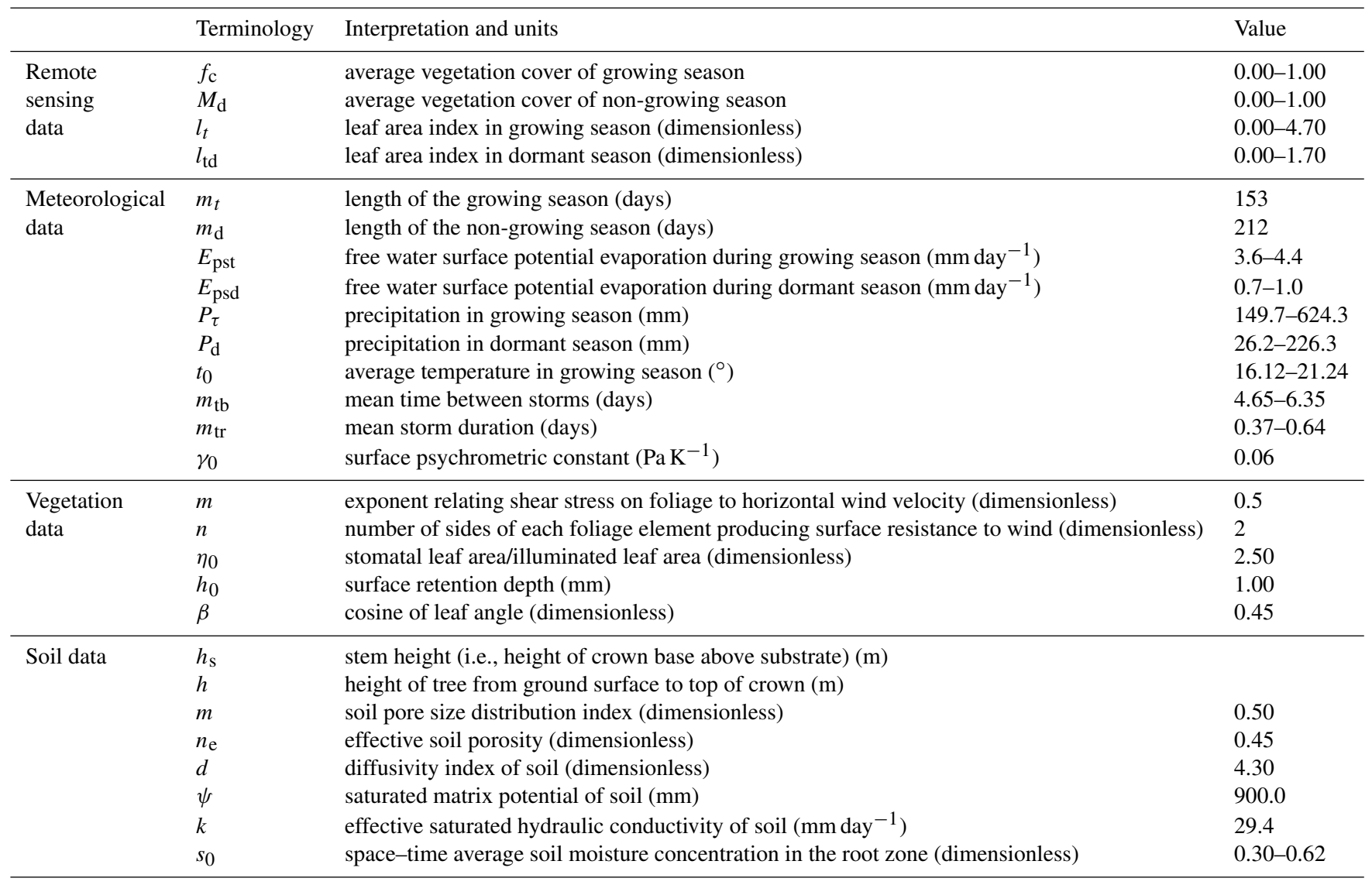

First, when climate and soil change in a short time period, the canopy cover will adjust its value to maximize the soil moisture. Second, as the timescales get longer, the species whose potential transpiration efficiency make the soil moisture highest will be selected through natural selection. Third, the soil properties will be altered to ensure the species get their maximum canopy cover (Eagleson, 2002; Hatton et al., 1997). These hypotheses mentioned two important canopy state variables, i.e., the canopy cover $(M)$ and canopy conductance $\left(k_{v}\right)$. Canopy conductance is defined as the ratio of potential rates of transpiration $E_{v}$ and soil surface evaporation $E_{\mathrm{ps}}$ (Eagleson, 1978d, 2002):

$k_{v}=\frac{E_{v}}{E_{\mathrm{ps}}}$

The potential evapotranspiration $E_{\mathrm{ps}}$ is calculated by Penman equation:

$\lambda E_{\mathrm{ps}}=\frac{\Delta R_{\mathrm{n}}+\rho c_{\mathrm{p}}\left[e_{\mathrm{s}}(T)-e\right] / r_{\mathrm{a}}}{\Delta+\gamma_{0}}$.

The canopy transpiration rate $E_{v}$ is calculated by PenmanMonteith equation: $\lambda E_{v}=\frac{\Delta R_{\mathrm{n}}+\rho c_{\mathrm{p}}\left[e_{\mathrm{s}}(T)-e\right] / r_{\mathrm{a}}}{\Delta+\gamma_{0}\left(1+r_{\mathrm{c}} / r_{\mathrm{a}}\right)}$,

where $E_{\mathrm{ps}}$ is the potential rate of evaporation from a wet simple surface $\left(\mathrm{mm} \mathrm{day}^{-1}\right) ; E_{v}$ is the rate of canopy transpiration $\left(\mathrm{mm} \mathrm{day}^{-1}\right) ; \lambda$ is the latent heat of vaporization of water $=2500 \mathrm{~J} \mathrm{~g}^{-1}\left(\right.$ at $\left.0{ }^{\circ} \mathrm{C}\right) ; \Delta$ is the slope of the saturation vapor pressure vs. temperature curve $\left(\mathrm{Pa} \mathrm{K}^{-1}\right) ; R_{\mathrm{n}}$ is the net solar radiation, $\mathrm{J} /\left(\mathrm{mm}^{2} \mathrm{day}^{-1}\right) ; \rho$ is the fluid mass density $\left(\mathrm{g} \mathrm{mm}^{-3}\right) ; c_{\mathrm{p}}$ is the specific heat of air at constant pressure, $\mathrm{J} /\left(\mathrm{g} \mathrm{K}^{-1}\right) ; e_{\mathrm{S}}(T)$ is the saturation vapor pressure at the temperature of the evaporation site $(\mathrm{Pa}) ; e$ is the partial pressure of water vapor $(\mathrm{Pa}) ; r_{\mathrm{a}}$ is the lumped atmospheric resistance over the $2 \mathrm{~m}$ above the canopy top (day $\mathrm{mm}^{-1}$ ); $r_{\mathrm{c}}$ is the lumped resistance to flow through the canopy which does not vary with water supply $\left(\right.$ day $\mathrm{mm}^{-1}$ ); and $\gamma_{0}$ is the surface psychrometric constant $\left(\mathrm{Pa} \mathrm{K}^{-1}\right)$.

When the stomas fully open, the canopy transpiration rate $E_{v}$ will reach its maximum value - potential canopy transpiration $E_{\mathrm{pv}}$ - thus making $k_{v}$ its maximum value as well, which is called the potential canopy conductance $k_{v}^{*}$ : 
$k_{v}^{*}=\frac{E_{\mathrm{pv}}}{E_{\mathrm{ps}}}=\frac{1+\Delta / \gamma_{0}}{1+\Delta / \gamma_{0}+(1-M)\left(\frac{r_{\mathrm{c}}}{r_{\mathrm{a}}}\right)_{M \rightarrow 0}+M\left(\frac{r_{\mathrm{c}}}{r_{\mathrm{a}}}\right)_{M=1}}$,

where $\left(r_{\mathrm{c}} / r_{\mathrm{a}}\right)_{M \rightarrow 0}$ is the resistance ratio for open canopies, which is related to the exponent relating shear stress on foliage to horizontal wind velocity and horizontal leaf area index. $\left(r_{\mathrm{c}} / r_{\mathrm{a}}\right)_{M=1}$ is the resistance ratio for closed $(M=1)$ canopies whose main influence factor is the ratio of stem height $h_{\mathrm{s}}$ and tree height $h$. According to Eq. (5) and explanations above, the resistance ratio can be fixed once the vegetation specie is given. The potential canopy conductance $k_{v}^{*}$ is inversely proportionate to the canopy cover $M$. The $k_{v}^{*}-M$ curve is called the water demand curve.

The relationship between $k_{v}^{*}$ and $M$ can also be described by the water balance equation. In the growing season, the average inflows and outflows of the soil column can be described as

$P_{\tau}-m_{v} E\left[E_{\mathrm{r}}\right]-\Delta S=m_{v} E\left[R_{\mathrm{s} j}\right]+E\left[E_{T \tau}\right]+m_{\tau} v-m_{\tau} w$,

where $P_{\tau}$ is the growing season precipitation $(\mathrm{mm}) ; m_{v}$ is the number of independent storm times (dimensionless); $E_{\mathrm{r}}$ is the storm surface retention depth $(\mathrm{mm}) ; R_{\mathrm{s} j}$ is the storm rainfall excess (mm); $\Delta S$ is the average carryover (from dormant season to growing season) soil moisture storage $(\mathrm{mm}) ; m_{\tau}$ is the growing season length (days); $v$ is the percolation to water table $\left(\mathrm{mm} \mathrm{day}^{-1}\right) ; w$ is the capillary rise from the water table $\left(\mathrm{mm} \mathrm{day}^{-1}\right)$; and $E[]$ indicates the expected value of [].

Some assumptions are made to describe each item (Eagleson, $1978 \mathrm{a}-\mathrm{g}$ ). Thus, the water balance of the growing season can be expressed as

$M k_{v}^{*}=\frac{V_{\mathrm{e}}}{m_{\mathrm{tb}} E_{\mathrm{ps}}}$,

where $V_{\mathrm{e}}$ is the volume of soil moisture (per unit of surface area) available for exchange with atmosphere during average inter-storm period $(\mathrm{mm})$, and $m_{\mathrm{tb}}$ is mean time between storms (h); more details can be found in the Appendix.

Equation (7) describes water supply in naturally selected canopy moisture state, while Eq. (5) describes water demand of fixed vegetation species. By drawing these two lines in a figure (Fig. 2), we can notice that the water demand grows with the increase of $M$, but as water is limited, water supply decreases under $M$ enhancement. The intersection point of these two lines is the theoretical optimal canopy cover and potential canopy conductance in the vegetation state space. This method is applied in each grid $(10 \mathrm{~km} \times 10 \mathrm{~km})$ of the NECT area.

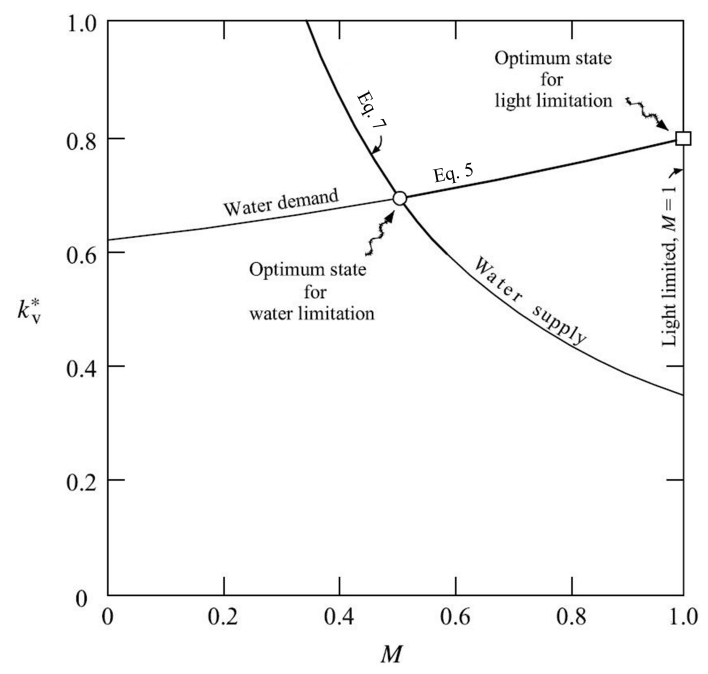

Figure 2. Optimum canopy state (from Eagleson, 2002).

\section{Results and discussion}

\subsection{Canopy cover of the NECT}

The observed canopy cover $M$ shows a significant gradient ranging from 1 in the eastern forests to 0 in the western desert (Fig. 3a).

The dark blue area is mainly the forests of the Changbai Mountains, where the average canopy cover reaches up to 0.83 . The light blue area is the Songnen Plain. The Songnen Plain is one of the most famous commodity grain bases, rich in corn, sorghum, soybean, wheat and paddies (Zhou and Wang, 2003), with the average canopy cover of 0.55. Farther westward, there is Horqin Sand, in which most of the vegetation is grass. Then, there is a narrow northeastsouthwest-oriented band with a relatively higher value (blue color) at around $120^{\circ} \mathrm{E}$, which is mainly caused by the elevation. The band is the location of Greater Khingan Range. The east slope of the Greater Khingan Range is very steep; thus, the maritime monsoon can bring a lot of rainfall, causing the existence of the forest ecosystem. However, most of the vegetation on the west slope is grass, mainly because of the gentle gradient and dry climate (Guo and Zhang, 2013). The grassland is the Inner Mongolia steppe.

The ecohydrological optimality theory is applied in this study to simulate theoretic optimal canopy cover $\left(M^{*}\right)$ of the NECT. As shown in Fig. 3b, the modeled canopy cover has the same trend with the actual $M$ but transitions more smoothly, which is mainly caused by the interpolation of meteorological data. The blank grids in the simulation result are due to the missing data of LAI. The result indicates that the average $M^{*}$ fits the average $M$ well (for forest, $M^{*}=0.822$ while $M=0.826$; for grassland, $M^{*}=0.353$ while $M=0.352$; the correlation coefficient between $M$ and $M^{*}$ is 0.81 ). The corresponding areas are highlighted in the 

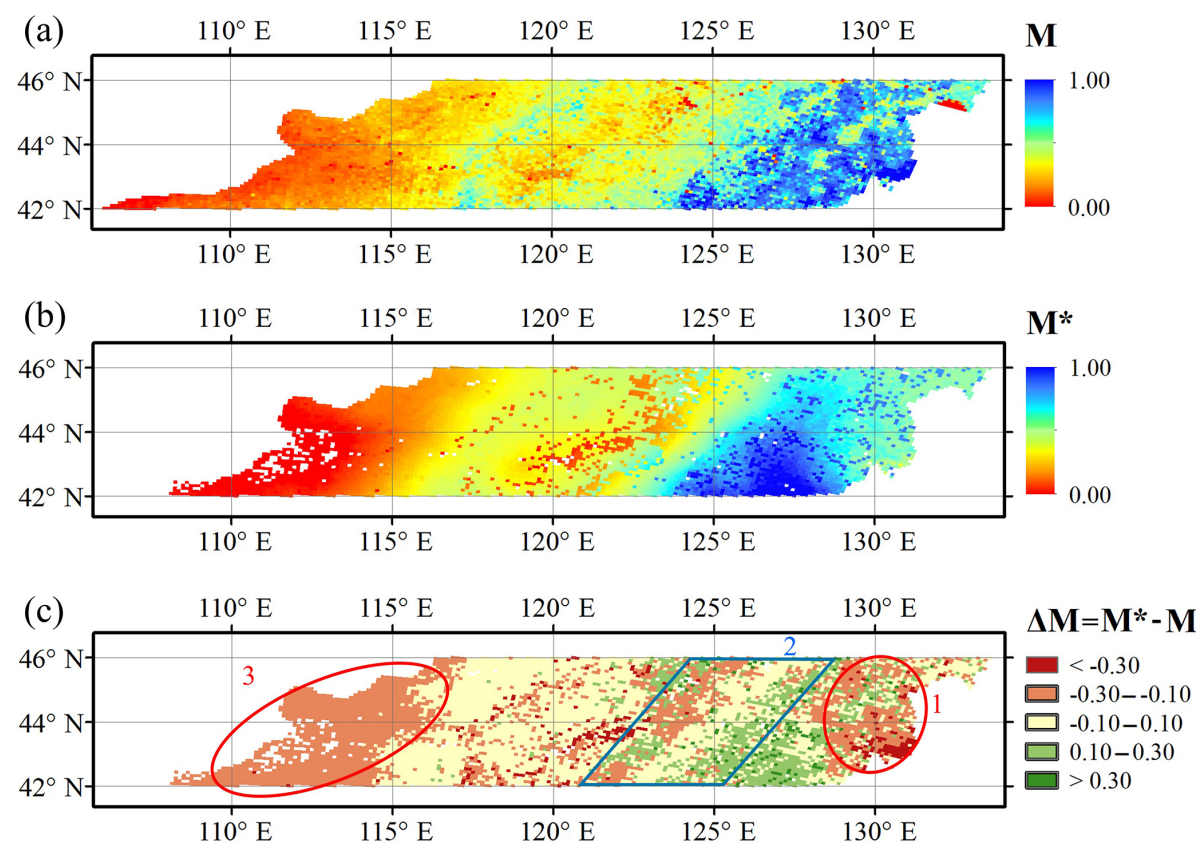

Figure 3. Spatial distribution of mean canopy cover from MODIS NDVI (a), optimal canopy cover (b) and their difference (c).

figure of spatial distribution of $\Delta M$, defined as $M^{*}$ minus $M$ (Fig. 3c). The spatial average $\Delta M$ is only -0.050 for the whole NECT area; meanwhile, there are $45.7 \%$ pixels of the NECT area where the $\Delta M$ value is between -0.1 and 0.1 . There are three regions where the differences between $M$ and $M^{*}$ are relatively large. Region 1 is the Yanbian Korean Autonomous Prefecture. The simulation result is relatively small mainly because of the forest protection project. The Natural Forest Protection Project (NFPP) has been conducted in northeastern China since 1998, aiming at protecting the natural forest resources (Wei et al., 2014). Yanbian forest acreage has increased by $800 \mathrm{~km}^{2}$ during the first stage of NFPP. The dark red area is the city of Hunchun. Hunchun is a representative nature reserve, and the forest acreage has increased by 9009 ha from 1999 to 2012 (Li, 2014). Region 2 is the southern Xilin Gol grassland. In the past decades, Xilin Gol grassland has been extremely dry and has been suffering from severe degradation (Tong et al., 2004). The Beijing-Tianjin Sand Source Control Project is undertaken to improve the canopy cover of degraded grassland. Over 66000 water source projects and 47000 water-saving irrigation projects increased the water supply of this area, thus contributing to the increase of vegetation activities (Yu et al., 2010). The irrigation part is not considered in Eagleson's water balance system, which leads to the deviation of the modeled results. In the crop region (the blue frame in Fig. 3c), some $M^{*}$ are higher than $M$, while some are lower. This is because of the close relationship between canopy cover and crop growth stage. The growth process of various crops is different, and the timing of plantation and harvesting is mainly affected by human intervention rather than natural processes
(Liu et al., 2013; Kim and Wang, 2005). Meanwhile, the water supply for the crop is not only from the natural hydrological cycle but also from agricultural irrigation, which is not considered in the theory.

The correlation coefficient $R$ between $M$ and $M^{*}$ is high, which indicates the ecohydrological optimality theory is applied well in the NECT during the long-term period. Previous studies suggest there are lagged relationships between NDVI and climate factors, and the time lags are different in different regions or different biomes (Braswell et al., 1997; Piao et al., 2003; Li et al., 2011; Hu et al., 2011; Bao et al., 2015). Figure 4 shows that, in the grassland area, the variation amplitude of $M$ is smaller than $M^{*}$, and the delay usually happens within a year, while in the forest area, there is a trend delay across the years. For example, $M^{*}$ increases from 2007 to 2009, but the increasing trend of $M$ does not appear until 2009 to 2010 . This can be explained by the vegetation adaptation strategy to climate changes. For example, the canopy cover might not increase immediately with the increasing precipitation but might increase in the next year. Eagleson's theory describes how vegetation adapts to climate change in a relatively long term (Eagleson, 2002). Once climate changes, it takes years for vegetation to reach its optimum canopy cover.

\subsection{Water balance components}

As the NECT spans a wide range from west to east, and the vegetation and climate vary significantly, the NECT is divided into three parts according to land cover types: forest, cropland and grassland (Ni and Zhang, 2000). The propor- 
Table 2. Water balance components of different land cover types.

\begin{tabular}{|c|c|c|c|c|c|c|c|}
\hline \multirow{3}{*}{ Result } & & \multicolumn{2}{|c|}{ Grassland } & \multicolumn{2}{|c|}{ Cropland } & \multicolumn{2}{|c|}{ Forests } \\
\hline & $M$ & \multicolumn{2}{|c|}{0.352} & \multicolumn{2}{|c|}{0.548} & \multicolumn{2}{|c|}{0.826} \\
\hline & $M^{*}$ & \multicolumn{2}{|c|}{0.353} & \multicolumn{2}{|c|}{0.557} & \multicolumn{2}{|c|}{0.822} \\
\hline \multirow{6}{*}{$\begin{array}{l}\text { Water balance } \\
\text { component }\end{array}$} & & $\mathrm{mm}$ & $/ P$ & $\mathrm{~mm}$ & $/ P$ & $\mathrm{~mm}$ & $/ \mathrm{P}$ \\
\hline & Precipitation & 253 & $100.00 \%$ & 414 & $100.00 \%$ & 478 & $100.00 \%$ \\
\hline & Interception & 29 & $11.61 \%$ & 39 & $9.29 \%$ & 68 & $14.24 \%$ \\
\hline & Runoff & 1 & $0.19 \%$ & 119 & $28.77 \%$ & 119 & $24.92 \%$ \\
\hline & $\Delta S$ & 91 & $36.29 \%$ & 14 & $3.34 \%$ & -74 & $-15.47 \%$ \\
\hline & Evaporation & 131 & $51.90 \%$ & 243 & $58.60 \%$ & 365 & $76.31 \%$ \\
\hline
\end{tabular}
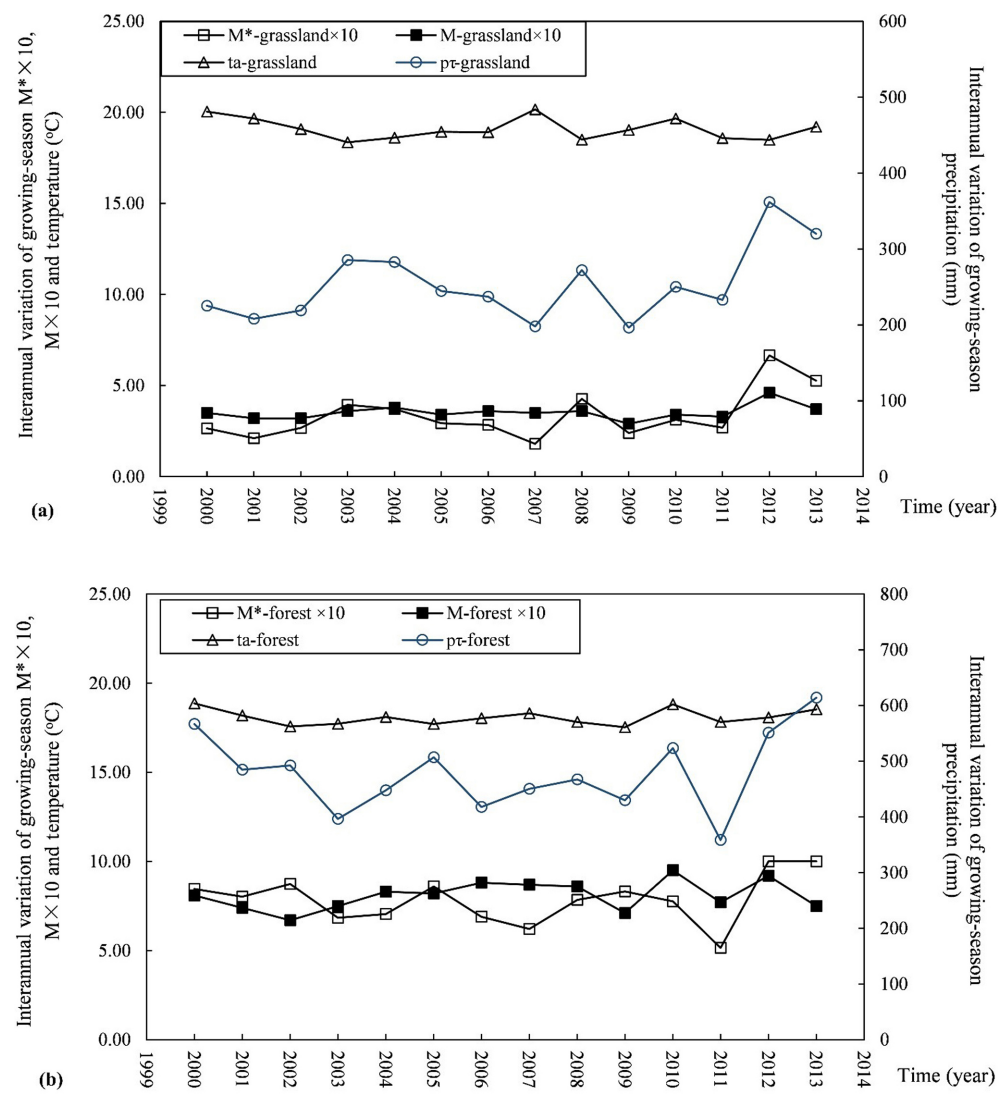

Figure 4. Variation of $M^{*}, M$, precipitation $\left(P_{\tau}\right)$ and air temperature $\left(t_{\mathrm{a}}\right)$ during 2000-2013: (a) grassland; (b) forest.

tions of the water balance components for the annual average growing season are calculated for each part based on Eq. (6), as shown in Table 2. According to the research conducted before, in the grassland area, the interception was 20.86 and $7.88 \%$ for shrub and grass, respectively (Peng et al., 2014), and the runoff of Xilin Gol grassland occupied around $0.046-1.8 \%$ (Wang et al., 2008a; Miao et al., 2008). In the forest area, the dominant tree species are Pinus koraiensis (Pk), Quercus mongolica (Qm), Populus davidiana (Pd) and B. platyphylla (Bp) (Chen, 2001; Zhang and Zhou, 2009). The interception consists of $19.61 \%$ for Pk and $14.97 \%$ for Bp in the Greater Khingan Range and $10.20 \%$ for Pk in the Changbai Mountains (Cai et al., 2008; Wang et al., 2006). The runoff coefficients of the Suifen River and Second Songhua River, both of which are located in the forest area, are around 20-30\% (Huang, 1999; Song, 2010). The simulated interception and runoff for both grassland and forest areas are consistent with previous studies, which demonstrates the reasonability of this theory. The negative value of $\Delta S$ in the forest area means a recharge of soil moisture. As the air temperature in the non-growing season is low, most of the precipitation is snow rather than rain, so the water is frozen in the soil and melts in the next spring (Fan et al., 2006; Yang et al., 2006). Therefore, most of the water is 

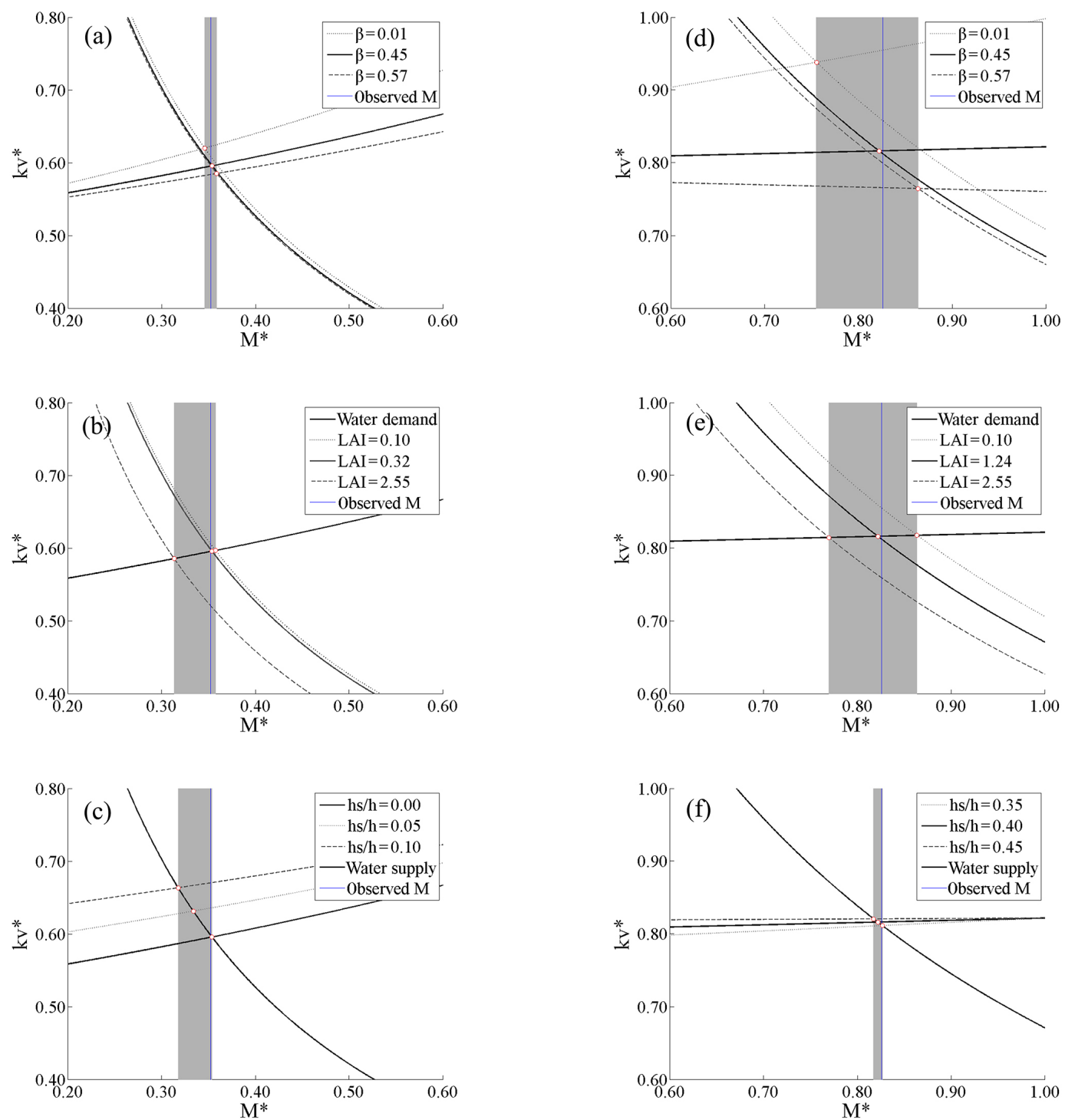

Figure 5. $M^{*}$ changes with $\beta$, LAI and $h_{\mathrm{S}} / h$ : (a)-(c) grassland; (d)-(f) forest. The shaded areas indicate the range of $M^{*}$ with the change of climate factors.

stored in the dormant season for the vegetation growth in the next growing season.

The rationality of the calculated proportions of water balance components for each part demonstrates the applicability of the optimality theory. By adapting this method, it is much easier to figure out the allocation of precipitation if the vegetation and soil conditions are known.

\subsection{Sensitivity of $M^{*}$ to vegetation properties}

LAI, $\beta$ and $h_{\mathrm{s}} / h$ control the physical and biological processes of plant canopies, such as interception and evaporation (Chen and Black, 1992; Asner, 1998; Huete et al., 2002). $\beta$ and LAI are the dominant parameters for the interception calculation, thus leading to the variance of water supply for vegetation growth. $\beta$ and $h_{\mathrm{s}} / h$ affect the plant evaporation by affecting the resistance ratio, which influences the water demand curve (Eagleson, 2002). The thresholds of the three parameters are from the experiments conducted before ( $\mathrm{Du}$, 2004; Wang et al., 2008b; Rauner, 1976; Eagleson, 2002). Figure 5 shows the different reactions of optimal canopy cover to vegetation species change between grassland and forest areas. $M^{*}$ increases with the increase of leaf angle and decrease of stem fraction and LAI. Mo et al. (2015) studied the relationship between vegetation properties and optimal canopy cover in Horqin Sand, China, and reached the same conclusion. In the grassland area, the water demand curve is more sensitive to the variation of $h_{\mathrm{s}} / h$ compared to $\beta . M^{*}$ decreases by 0.037 as $h_{\mathrm{s}} / h$ increases by 0.10 . The water supply curve changes a lot with the change of LAI 

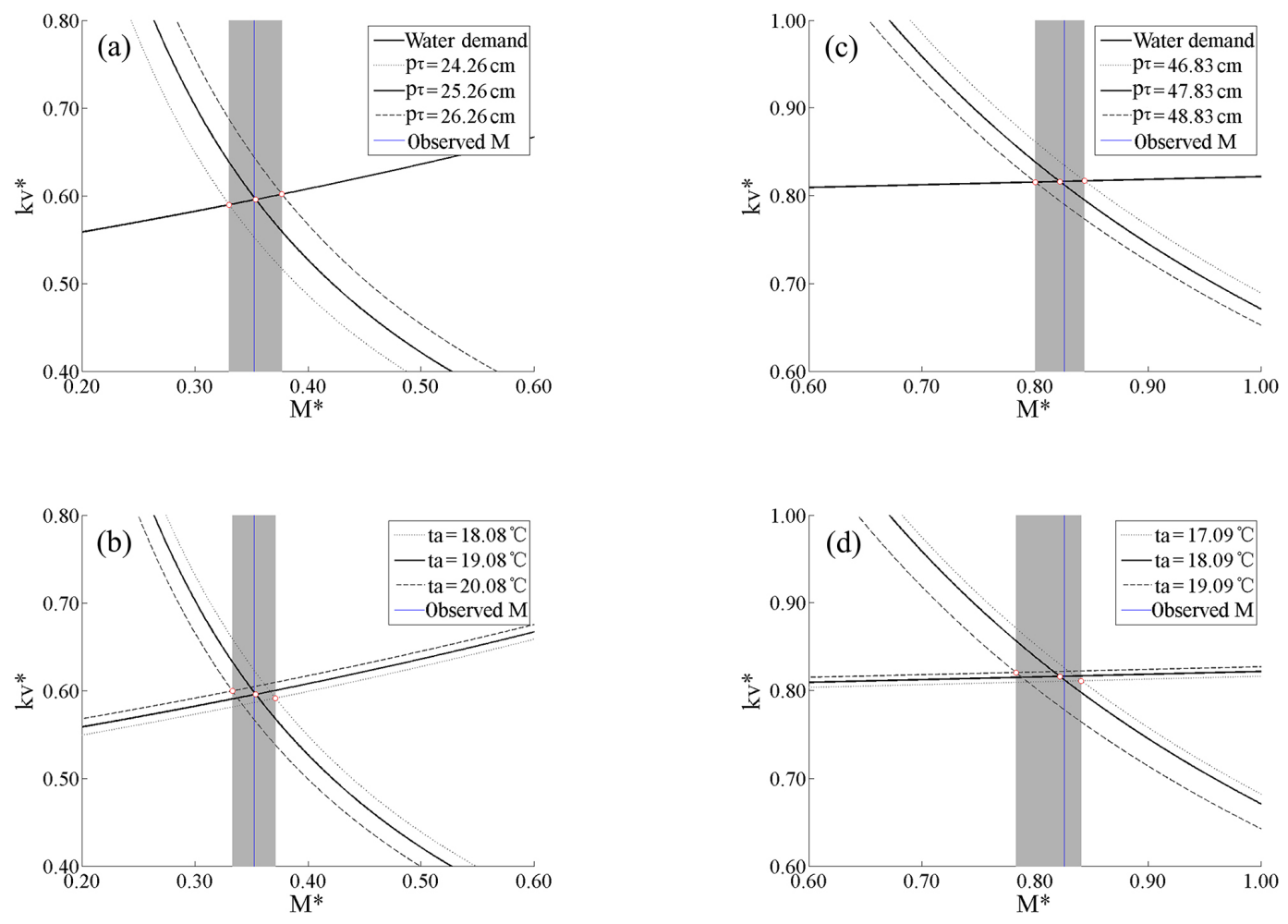

Figure 6. $M^{*}$ changes with precipitation $\left(P_{\tau}\right)$ and air temperature $\left(t_{\mathrm{a}}\right)$ : $(\mathbf{a}, \mathbf{b})$ grassland; $(\mathbf{c}, \mathbf{d})$ forest. The shaded areas indicate the range of $M^{*}$ with the change of vegetation properties.

but slightly with $\beta$ or $h_{\mathrm{s}} / h$. In the forest area, $M^{*}$ is less sensitive to $h_{\mathrm{s}} / h$ than $\beta$ or LAI. Because the average stem fraction of trees $(0.4-0.5)$ is usually larger than grasslands or shrub (0.0-0.1), the water demand curve is much gentler (Eagleson, 2002) and changes little with $h_{\mathrm{s}} / h$. The forest interception takes up $14.24 \%$ of precipitation during the growing season, which is larger than that of grassland. $M^{*}$ increases by 0.108 and 0.094 with a decrease of 0.56 in $\beta$ and 2.45 in LAI, respectively.

The sensitivity of $M^{*}$ to vegetation properties can be used to offer advice about species choice and plant density to ecorestoration projects. If the purpose is to increase canopy cover, different strategies should be conducted in different areas. For the grassland area, shrubby or herbaceous plants with low $h_{\mathrm{s}} / h$ value are more welcome. Nevertheless, in the forest area, as $h_{\mathrm{s}} / h$ does not affect canopy cover that much, more considerations should be taken when choosing the species with relatively lower $\beta$ and LAI values. However, vegetation with a larger canopy cover always requires more water to maintain functions (Woodward and Mckee, 1991; Zhang and Zhou, 2011). If the plant species are determined, the optimum canopy cover can be calculated and the upper limit for plant density can be estimated.

\subsection{Sensitivity of $M^{*}$ to climate factors}

Studies of the relationship between climate factors and vegetation growth conditions reveal that precipitation and temperature are the two dominant factors that affect $M^{*}$ (Ichii et al., 2002; Liu and Li, 2015). Under this framework, the variation of precipitation $\left(P_{\tau}\right)$ affects the availability of water, thus changing water supply curve; air temperature $\left(t_{\mathrm{a}}\right)$ affects not only water supply but also water demand, through changing resistance ratio and evaporation (Fig. 6). In the grassland area, $M^{*}$ exhibits a positive relationship with precipitation but a negative relationship with air temperature (Fig. 6a and $b$ ), which is consistent with studies conducted before ( $\mathrm{He}$ et al., 2015; Peng et al., 2012). This can be explained by the limited water supply in arid and semi-arid regions, and the increase of air temperature enhances transpiration and evaporation intensity (Duan et al., 2011; Mao et al., 2012). The variation of grassland $M^{*}$ during 2000-2013 (Fig. 4a) also shows a similar trend of precipitation, while the trend of air temperature is different from that of precipitation in most years. In the forest area, $M^{*}$ increases with the increase of precipitation and decrease of air temperature, but the variance of grassland $M^{*}$ is less than that of forest with the same range of air temperature, which indicates the forest plants are more sensitive to air temperature than grassland. However, the result is different from previous studies. Most correlation anal- 
Table 3. The variance of inputs and their corresponding $M^{*}$.

\begin{tabular}{llcc}
\hline Inputs & Variation range & Grassland $M^{*}$ & Forest $M^{*}$ \\
\hline$\beta$ & $0.01-0.57$ & $0.346-0.358$ & $0.755-0.863$ \\
LAI & $0.10-2.55$ & $0.313-0.357$ & $0.770-0.864$ \\
$h_{\mathrm{S}} / h$ & $0.00-0.10$ (grassland); $0.35-0.45$ (forest) & $0.317-0.354$ & $0.817-0.827$ \\
$P_{t}$ & $24.26-26.26$ (grassland); 46.83-48.83 (forest) & $0.330-0.377$ & $0.800-0.844$ \\
$t_{\mathrm{a}}$ & $18.08-20.08$ (grassland); 17.09-19.09 (forest) & $0.333-0.371$ & $0.783-0.841$ \\
\hline
\end{tabular}

yses of NDVI with air temperature and precipitation show that, in the forest area, NDVI increases with the increase of air temperature and decrease of precipitation, because air temperature is the dominant factor in humid areas, and the light-use efficiency increases under elevated air temperatures (Peng et al., 2012; Wang et al., 2014; Liu et al., 2011). The difference may be caused by the deficient hypotheses of the theory. Under this framework, the surface runoff is assumed to be Hortonian, but in most humid areas, the runoff is saturation excess. The improper hypothetical runoff mechanism leads to the deviation of runoff in water-sufficient areas, thus causing the deviation of the water supply curve.

\section{Conclusion}

In this study, remote-sensed NDVI is used to generate the actual canopy cover of the NECT, while the ecohydrological optimality method has been applied to calculate the optimal canopy cover. The proportions of water balance components have been explored, as well as the influence of vegetation properties and climate factors on optimal canopy cover. The main conclusions are summarized as follows:

1. The observed canopy cover $M$ shows a significant decreasing gradient from eastern forests to the west. The modeled canopy cover $M^{*}$ has the same trend with $M$ but transitions more smoothly, which is mainly caused by the interpolation of meteorological data. The relatively lower $M^{*}$ in Yanbian Korean Autonomous Prefecture and Xilin Gol grassland is mainly because of human activity. The correlation coefficient $R$ between $M$ and $M^{*}$ is 0.81 , which indicates the ecohydrological optimality theory is applied well in the NECT during the long-term period. There is a 2-year lag between $M^{*}$ and $M$ during 2002-2012, due to the long-term adaptation strategy of vegetation to climate change.
2. The proportions of the water balance components are calculated for three parts: forest, cropland and grassland. The simulated results are within the observed range, which demonstrates the reasonability of this theory. By adapting this method, it is much easier to figure out the allocation of precipitation with fixed vegetation and soil conditions.

3. $M^{*}$ has a positive relationship with $\beta$ and a negative relationship with $h_{\mathrm{s}} / h$ and LAI. Grassland plants are more sensitive to $h_{\mathrm{s}} / h$ and LAI compared to $\beta$, while forest plants are more sensitive to $\beta$ and LAI than $h_{\mathrm{s}} / h$. The sensitivity of $M^{*}$ to vegetation properties can be used to offer advice about species choice and plant density for ecorestoration projects.

4. Precipitation and temperature are the two dominant climate factors that affect $M^{*} . M^{*}$ increases with the increase of precipitation and decrease of air temperature. Eagleson's ecohydrological optimality theory offers an opportunity to explore the quantitative relationship between vegetation and climate factors from the mechanism, but the runoff mechanism description in the wet region still needs improvement.

Data availability. The MODIS satellite products used in this study are available at http://reverb.echo.nasa.gov/; the meteorological data are available at http://data.cma.cn/. 


\section{Appendix A: Algorithm of optimal canopy cover}

Eagleson made several assumptions for each item of Eq. (4). The Poisson precipitation model was used to simulate the precipitation process by random storm depth and duration (Eagleson, 1978b). The probability density functions of storm depth and storm duration are incomplete gamma and exponential distributions, respectively. The growing season precipitation can be expressed as

$P_{\tau}=m_{v} m_{h}$,

where $m_{h}$ is the mean storm depth (mm).

Surface retention $m_{v} E_{\mathrm{r}}$ is the water held on the surface during the rainstorm of duration. The total surface retention is proportioned by bare soil and vegetation canopy:

$E\left[E_{\mathrm{r}}\right]=(1-M) E\left[E_{\mathrm{rs}}\right]+M E\left[E_{\mathrm{rv}}\right]$,

respectively. $E\left[E_{\mathrm{r}}\right]$ can be further expressed as

$E\left[E_{\mathrm{r}}\right]=\left(1+M \eta_{0} \beta L_{t}\right) h_{0}=\overline{h_{0}}$,

where $\eta_{0}$ is the ratio of stomatal leaf area to illuminated leaf area (dimensionless); $\beta$ is the cosine of leaf angle (dimensionless); $L_{t}$ is the foliage area index (dimensionless); and $h_{0}$ is the surface retention depth (mm). The interception depth retained on the horizontal projection of leaves is assumed to be $1.00 \mathrm{~cm}$ (Eagleson, 1978d).

Average carryover soil moisture storage $\Delta S(\mathrm{~mm})$ is determined by the soil profile and seasonality (Eagleson, 2002):

$\Delta S=-\left[P_{\mathrm{d}}-(1-M) E_{\mathrm{psd}} m_{\mathrm{d}}-Y_{\mathrm{d}}\right]$,

where $P_{\mathrm{d}}(\mathrm{mm}), E_{\mathrm{psd}}\left(\mathrm{mm} \mathrm{day}^{-1}\right), m_{\mathrm{d}}$ (days) and $Y_{\mathrm{d}}$ (days) are the precipitation, evaporation, mean length and runoff in the non-growing season, respectively.

Assume that there is no surface inflow from outside of the region, and the surface runoff is Hortonian (Eagleson, 1978e). When the storm intensity $m_{\mathrm{i}}$ and storm duration $m_{\mathrm{tr}}$ are independent random variables, the storm surface runoff $m_{v} R_{\mathrm{s} j}$ is

$E\left(R_{\mathrm{s} j}\right)=m_{h} e^{-G-2 \sigma^{3 / 2}}$,

where

$G \equiv \omega K(1)\left(\frac{1+s_{0}^{c}}{2}\right)$ $\sigma \equiv\left[\frac{5 n_{\mathrm{e}} \lambda_{0}^{2} K(1) \psi(1)\left(1-s_{0}\right)^{2} \phi_{i}\left(d, s_{0}\right)}{6 \pi \delta m \kappa_{0}^{2}}\right]$,

where $s_{0}$ is the space-time average soil moisture in the root zone (dimensionless); $\omega=1 / m_{\mathrm{i}} ; K(1)$ is the effective saturated hydraulic conductivity of soil $\left(\mathrm{cm} \mathrm{day}^{-1}\right) ; n_{\mathrm{e}}$ is effective soil porosity (dimensionless); $\lambda_{0}$ is scale parameter of probability density function of storm depth $\left(\mathrm{cm}^{-1}\right) ; \psi(1)$ is the saturated matrix potential of soil $(\mathrm{cm}) ; \phi_{i}$ is the sorption diffusivity (dimensionless); $\delta=1 / m_{\mathrm{tr}}\left(\right.$ day $\left.^{-1}\right) ; m$ is the soil pore size distribution index (dimensionless); and $\kappa_{0}$ is the shape parameter or distribution index of storm depth (dimensionless).

Evapotranspiration consists of bare soil evaporation and vegetal transpiration:

$E\left[E_{T \tau}\right]=m_{v} m_{\mathrm{tb}} E_{\mathrm{ps} \tau}\left[(1-M) \beta_{\mathrm{s}}+M k_{v}^{*} \beta_{v}\right]$,

where $m_{\mathrm{tb}}$ is the mean time between storms (days); $E_{\mathrm{ps} \tau}$ is the potential free water surface potential evaporation during the growing season $\left(\mathrm{mm} \mathrm{day}^{-1}\right) ;$ and $\beta_{\mathrm{s}}$ and $\beta_{v}$ are the bare soil evaporation efficiency and canopy transpiration efficiency, respectively (Eagleson, 1978d).

The percolation rate is mainly affected by $s_{0}$ (Eagleson, 1978f):

$v\left(s_{0}\right)=K(1) s_{0}^{\mathrm{c}}$.

The capillary rise is considered to be 0 due to the deep water table in the NECT.

Using Eqs. (A1)-(A9), Eq. (4) gives the water balance of growing season as

$$
\begin{aligned}
1 & -e^{-G-2 \sigma^{3 / 2}}-\frac{\overline{h_{0}}}{m_{h}}+\frac{\Delta S}{m_{v} m_{h}} \\
= & \frac{m_{\mathrm{tb}} E_{\mathrm{ps}}}{m_{h}}\left[(1-M) \beta_{\mathrm{s}}+M k_{v}^{*} \beta_{v}\right]+\frac{m_{\tau} K(1)}{P_{\tau}} s_{0}^{\mathrm{c}} .
\end{aligned}
$$

$\beta_{v}$ is equal to 1.0 when the water condition reaches optimal state. When the bare soil evaporation is ignored, Eq. (A10) can be simplified into

$M k_{v}^{*}=\frac{V_{\mathrm{e}}}{m_{\mathrm{tb}} E_{\mathrm{ps}}}$,

where

$V_{\mathrm{e}}=m_{h}-m_{h} e^{-G-2 \sigma^{3 / 2}}-\overline{h_{0}}+\frac{\Delta S}{m_{v}}-\frac{m_{\tau} K(1)}{P_{\tau}} s_{0}^{\mathrm{c}}$. 
Competing interests. The authors declare that they have no conflict of interest.

Acknowledgements. This work was supported by National Natural Science Foundation (grant nos. 51479088, 41630856).

Edited by: L. Wang

Reviewed by: M. Coenders-Gerrits and one anonymous referee

\section{References}

Allen, R. G.: Crop evapotranspiration: guidelines for computing crop water requirements, xxvi, Food and Agriculture Organization of the United Nations, Rome, 300 pp., 1998.

Asner, G. P.: Biophysical and Biochemical Sources of Variability in Canopy Reflectance, Remote Sens. Environ., 64, 234-253, 1998.

Austin, A. T. and Sala, O. E.: Carbon and nitrogen dynamics across a natural precipitation gradient in Patagonia, Argentina, J. Veg. Sci., 13, 351-360, 2002.

Bao, G., Bao, Y., Sanjjava, A., Qin, Z., Zhou, Y., and Xu, G.: NDVIindicated long-term vegetation dynamics in Mongolia and their response to climate change at biome scale, Int. J. Climatol., 35, 4293-4306, 2015.

Baret, F., Clevers, J. G. P. W., and Steven, M. D.: The robustness of canopy gap fraction estimates from red and near-infrared reflectances: A comparison of approaches, Remote Sens. Environ., 54, 141-151, 1995.

Braswell, B. H., Schimel, D. S., Linder, E., and Moore, B.: The Response of Global Terrestrial Ecosystems to Interannual Temperature Variability, Science, 278, 870-873, 1997.

Cai, T., Sheng, H., and Cui, X.: Rainfall redistribution of a virgin Pinus koraiensis forest and secondary Betula platyphylla forest in Northeast China, Front. Forest. China, 3, 189-193, doi:10.1007/s11461-008-0022-y, 2008.

Canadell, J. G., Steffen, W. L., and White, P. S.: IGBP/GCTE terrestrial transects: dynamics of terrestrial ecosystems under environmental change- introduction, J. Veg. Sci., 13, 298-300, 2002.

Carlson, T. N. and Ripley, D. A.: On the relation between NDVI, fractional vegetation cover, and leaf area index?, Remote Sens. Environ., 62, 241-252, 1997.

Chen, J. M. and Black, T. A.: Defining leaf area index for non-flat leaves, Plant Cell Environ., 15, 421-429, 1992.

Chen, X.: Change of tree diversity on Northeast China Transect (NECT), Biodivers. Conserv., 10, 1087-1096, 2001.

Dorman, M., Svoray, T., and Perevolotsky, A.: Homogenization in forest performance across an environmental gradient - The interplay between rainfall and topographic aspect, Forest Ecol. Manage., 310, 256-266, 2013.

$\mathrm{Du}$, J.: Approach to the Phenotypic Plasticity of Leymus chinensis Population Responding to Grazing[D]. Northeast Normal University, 2004. (in Chinese)

Duan, H., Yan, C., Tsunekawa, A., Song, X., Li, S., and Xie, J.: Assessing vegetation dynamics in the Three-North Shelter Forest region of China using AVHRR NDVI data (SCI), Environ. Earth Sci., 64, 1011-1020, 2011.

Eagleson, P. S.: Climate, soil, and vegetation: 1. Introduction to water balance dynamics, Water Resour. Res., 14, 705-712, 1978a.
Eagleson, P. S.: Climate, soil, and vegetation: 2. The distribution of annual precipitation derived from observed storm sequences, Water Resour. Res., 14, 713-721, 1978b.

Eagleson, P. S.: Climate, soil, and vegetation: 3. A simplified model of soil moisture movement in the liquid phase, Water Resour. Res., 14, 722-730, 1978c.

Eagleson, P. S.: Climate, soil, and vegetation: 4. The expected value of annual evapotranspiration, Water Resour. Res., 14, 731-739, 1978d.

Eagleson, P. S.: Climate, soil, and vegetation: 5. A derived distribution of storm surface runoff, Water Resour. Res., 14, 741-748, 1978e.

Eagleson, P. S.: Climate, soil, and vegetation: 6. Dynamics of the annual water balance, Water Resour. Res., 14, 749-764, $1978 \mathrm{f}$.

Eagleson, P. S.: Climate, soil, and vegetation: 7. A derived distribution of annual water yield, Water Resour. Res., 14, 765-776, $1978 \mathrm{~g}$.

Eagleson, P. S.: Ecological optimality in water-limited natural soilvegetation systems: 1 . Theory and hypothesis, Water Resour. Res., 18, 325-340, 1982.

Eagleson, P. S.: Ecohydrology: Darwinian expression of vegetation form and function, Cambridge University Press, Cambridge, 2002.

Eagleson, P. S. and Tellers, T. E.: Ecological optimality in waterlimited natural soil-vegetation systems: 2 . Tests and applications, Water Resour. Res., 18, 341-354, 1982.

Fan, S., Gao, Y., Cheng, Y., and Bai, Q.: Research of plot testing for effects of the woods and grass vegetation on runoff, J. Shandong Agr. Univers., 37, 43-47, 2006.

Fontana, F., Rixen, C., Jonas, T., Aberegg, G. and Wunderle, S.: Alpine Grassland Phenology as Seen in AVHRR, VEGETATION, and MODIS NDVI Time Series - a Comparison with In Situ Measurements, Sensors, 8, 2833-2853, 2008.

Füssler, J. S. and Gassmann, F.: On the role of dynamic atmosphere-vegetation interactions under increasing radiative forcing, Global Ecol. Biogeogr., 9, 337-349, 2000.

Graetz, R. D.: The nature and significance of the feedback of changes in terrestrial vegetation on global atmospheric and climatic change, Climatic Change, 18, 147-173, 1991.

Guo, X. Y. and Zhang, H. Y.: The Vegetation Dynamic Research Under of Eco-geographical Region Framework on Greater Khingan Mountains, Scient. Geogr. Sin., 33, 181-188, 2013.

Gutman, G. and Ignatov, A.: The derivation of the green vegetation fraction from NOAA/AVHRR data for use in numerical weather prediction models, Int. J. Remote Sens., 19, 1533-1543, 1998.

Hatton, T. J., Salvucci, G. D., and Wu, H. I.: Eagleson's optimality theory of an ecohydrological equilibrium: quo vadis?, Funct Ecol., 11, 665-674, 1997.

He, B., Chen, A., Wang, H., and Wang, Q.: Dynamic Response of Satellite-Derived Vegetation Growth to Climate Change in the Three North Shelter Forest Region in China, Remote Sensing, 7, 9998-10016, 2015.

Hmimina, G., Dufrêne, E., Pontailler, J. Y., Delpierre, N., Aubinet, M., Caquet, B., De Grandcourt, A., Burban, B., Flechard, C., and Granier, A.: Evaluation of the potential of MODIS satellite data to predict vegetation phenology in different biomes: An investigation using ground-based NDVI measurements, Remote Sens. Environ., 132, 145-158, 2013. 
Hu, M., Mao, F., Sun, H., and Hou, Y.: Study of normalized difference vegetation index variation and its correlation with climate factors in the three-river-source region, Int. J. Appl. Earth Obs. Geoinf., 13, 24-33, 2011.

Huang, G.: Impact of climate change on water resources of international rivers in northeastern China, Acta Geogr. Sin., 66, 152156, doi:10.11821/xb1999S1020, 1999.

Huete, A., Didan, K., Miura, T., Rodriguez, E. P., Gao, X., and Ferreira, L. G.: Overview of the radiometric and biophysical performance of the MODIS vegetation indices, Remote Sens. Environ., 83, 195-213, 2002.

Ichii, K.: Global correlation analysis for NDVI and climatic variables and NDVI trends: 1982-1990, Int. J. Remote Sens., 23, 3873-3878, 2002.

Ichii, K., Kawabata, A., and Yamaguchi, Y.: Global correlation analysis for NDVI and climatic variables and NDVI trends: 19821990, Int. J. Remote Sens., 23, 3873-3878, 2002.

Jiang, Z., Huete, A. R., Chen, J., Chen, Y., Li, J., Yan, G., and Zhang, X.: Analysis of NDVI and scaled difference vegetation index retrievals of vegetation fraction, Remote Sens. Environ., 101, 366-378, 2006.

Kerkhoff, A. J., Martens, S. N., and Milne, B. T.: An ecological evaluation of Eagleson's optimality hypotheses, Funct. Ecol., 18, 404-413, 2004.

Kim, Y. and Wang, G.: Modeling seasonal vegetation variation and its validation against Moderate Resolution Imaging Spectroradiometer (MODIS) observations over North America, J. Geophys. Res., 110, D04106, doi:10.1029/2004JD005436, 2005.

Koch, G. W., Scholes, R. J., Steffen, W. L., Vitousek, P. M. and Walker, B. H.: The IGBP terrestrial transects: science plan. International Geosphere-Biosphere Report 36, Programme, Stockholm, https://getsemaberri.files.wordpress.com/ 2017/04/20172718.pdf (last access: May 2017), 1995a.

Koch, G., Vitousek, P., Steffen, W., and Walker, B.: Terrestrial transects for global change research, Vegetatio, 121, 53-65, 1995b.

Li, B., Tao, S., and Dawson, R. W.: Relations between AVHRR NDVI and ecoclimatic parameters in China, Int. J. Remote Sens., 23, 989-999, 2002.

Li, S., Zhao, Z., Wang, Y., and Wang, Y.: Identifying spatial patterns of synchronization between NDVI and climatic determinants using joint recurrence plots, Environ. Earth Sci., 64, 851859,2011

Li, X.: Study on demonstration and construction of NFPP effect evaluation system in Yanbian Forest Region, PhD thesis, Northeast Forestry University, Harbin, China, 2014.

Liu, C., Shang, J., Vachon, P., and Mcnairn, H.: Multiyear Crop Monitoring Using Polarimetric RADARSAT-2 Data, IEEE T. Geosci. Remote, 51, 2227-2240, 2013.

Liu, W., Cai, T., Ju, C., Fu, G., Yao, Y., and Cui, X.: Assessing vegetation dynamics and their relationships with climatic variability in Heilongjiang Province, northeast China, Environ. Earth Sci., 64, 2013-2024, 2011.

Liu, Y. and Li, S.: Spatial and Temporal Patterns of Global NDVI Trends: Correlations with Climate and Human Factors, Remote Sensing, 7, 13233-13250, 2015.

Liu, Z., Notaro, M., Kutzbach, J., and Liu, N.: Assessing Global Vegetation-Climate Feedbacks from Observations, J. Climate, 19, 787-814, doi:10.1175/JCLI3658.1, 2006.
Lotsch, A., Friedl, M., Anderson, B., and Tucker, C.: Coupled vegetation-precipitation variability observed from satellite and climate records, Geophys. Res. Lett., 30, 107-218, 2003.

Mao, D., Wang, Z., Luo, L., and Ren, C.: Integrating AVHRR and MODIS data to monitor NDVI changes and their relationships with climatic parameters in Northeast China, Int. J. Appl. Earth Obs. Geoinf., 18, 528-536, 2012.

Mcpherson, R. A.: A review of vegetation-atmosphere interactions and their influences on mesoscale phenomena, Prog. Phys. Geogr., 31, 261-285, 2007.

Miao, B. L., Liang, C. Z., Wang, W., Wang, L. X., and Yun, W. L.: Effects of vegetation on degradation surface runoff of typical steppe, Res. Soil Water Conserv., 22, 10-14, 2008.

Mo, K., Cong, Z., and Lei, H.: Optimal vegetation cover in the Horqin Sands, China, Ecohydrology, 9, 700-711, doi:10.1002/eco.1668, 2015.

Myoung, B., Choi, Y. S., and Park, S. K.: A review on vegetation models and applicability to climate simulations at regional scale, Asia-Pac. J. Atmos. Sci., 47, 463-475, 2011.

Ni, J. and Zhang, X. S.: Climate variability, ecological gradient and the Northeast China Transect (NECT), J. Arid Environ., 46, 313 325, 2000.

Nie, Q., Xu, J., Ji, M., Cao, L., Yang, Y., and Hong, Y.: The vegetation coverage dynamic coupling with climatic factors in Northeast China Transect, Environ. Manage., 50, 405-417, doi:10.1007/s00267-012-9885-7, 2012.

Park, H. S. and Sohn, B. J.: Recent trends in changes of vegetation over East Asia coupled with temperature and rainfall variations, J. Geophys. Res.-Atmos., 115, 1307-1314, 2010.

Peng, H., Li, X., and Tong, S.: Effects of shrub (Caragana microphalla Lam.) encroachment on water redistribution and utilization in the typical steppe of Inner Mongolia, Acta Ecol. Sin., 34, 2256-2265, 2014.

Peng, J., Dong, W., Yuan, W., and Zhang, Y.: Responses of Grassland and Forest to Temperature and Precipitation Changes in Northeast China, Adv. Atmos. Sci., 29, 1063-1077, 2012.

Piao, S., Fang, J., Zhou, L., Guo, Q., Henderson, M., Ji, W., Li, Y., and Tao, S.: Interannual variations of monthly and seasonal normalized difference vegetation index (NDVI) in China from 1982 to 1999, J. Geophys. Res.-Atmos., 108, 4401, doi:10.1029/2002JD002848, 2003.

Piao, S., Mohammat, A., Fang, J., Cai, Q., and Feng, J.: NDVIbased increase in growth of temperate grasslands and its responses to climate changes in China, Global Environ. Change, 16, 340-348, 2006.

Piao, S., Wang, X., Ciais, P., Zhu, B., Wang, T., and Liu, J.: Changes in satellite-derived vegetation growth trend in temperate and boreal Eurasia from 1982 to 2006, Global Change Biol., 17, 32283239, 2011.

Rauner, J. L.: Vegetation and the Atmosphere, in: vol. 2, Case Studies, edited by: Monteith, J. L., Academic Press, New York, 241264, 1976.

Schultz, P. A. and Halpert, M. S.: Global correlation of temperature, NDVI and precipitation, Adv. Space Res., 13, 277-280, 1993.

Shao, W., Yang, D., Sun, F., and Wang, J.: Analyzing the Regional Soil-Vegetation-Atmosphere Interaction Using Both the Eagleson and Budyko's Water Balance Models, Proced. Environ. Sci., 10, 1908-1913, 2011. 
Song, X.: Precipitation, streamflow and sediment transport changes and its response to human activities in Songhua basin, Graduate University of Chinese Academy of Sciences, Beijing, China, 2010.

Tong, C., Wu, J., Yong, S., Yang, J., and Yong, W.: A landscapescale assessment of steppe degradation in the Xilin River basin, Inner Mongolia, China, J. Arid Environ., 59, 133-149, 2004.

Wang, A., Pei, T., Jin, C., and Guan, D.: Estimation of rainfall interception by broad-leaved Korean pine forest in Changbai Mountains, Chinese J. Appl. Ecol., 17, 1403-1407, 2006.

Wang, J., Rich, P. M., and Price, K. P.: Temporal responses of NDVI to precipitation and temperature in the central Great Plains, USA, Int. J. Remote Sens., 24, 2345-2364, 2003.

Wang, Q., Zhang, B., Zhang, Z., Zhang, X., and Dai, S.: The ThreeNorth Shelterbelt Program and Dynamic Changes in Vegetation Cover, J. Resour. Ecol., 5, 53-59, 2014.

Wang, Y. L., Yun, W. L., Miao, B. L., Liang, C. Z., and Wang, W. : The Pattern and Dynamics of Surface Runoff in the Typical Steppe of Inner Mongolia, Res. Soil Water Conserv., 15, 114115, 2008a.

Wang, Y. F., Mo, X. G., Hao, Y. B., Guo, R. P., and Huang, X. $\mathrm{Z}$.: Simulating seasonal and interannual variations of ecosystem evapotranspiration and its components in Inner Mongolia steppe with VIP model, J. Plant Ecol., 32, 1052-1060, 2008 b.
Wei, Y., Yu, D., Lewis, B. J., Zhou, L., Zhou, W., Fang, X., Zhao, W., Wu, S., and Dai, L.: Forest Carbon Storage and Tree Carbon Pool Dynamics under Natural Forest Protection Program in Northeastern China, Chinese Geogr. Sci., 24, 397-405, 2014.

Woodward, F. I. and Mckee, I. F.: Vegetation and climate, Environ. Int., 17, 535-546, 1991.

Yang, H., Pei, T., Guan, D., Jin, C., and Wang, A.: Soil moisture dynamics under broad-leaved Korean pine forest in Changbai Mountains, Chinese J. Appl. Ecol., 17, 587-591, 2006.

Yu, X. X., Gu, J. J., and Yue, Y. J.: Benefit evaluation on forestry ecological projects, Science Press, Beijing, China, 2010.

Yuan, X., Li, L., Chen, X., and Shi, H.: Effects of Precipitation Intensity and Temperature on NDVI-Based Grass Change over Northern China during the Period from 1982 to 2011, Remote Sensing, 7, 10164-10183, 2015.

Zhang, Y. and Zhou, G.: Exploring the effects of water on vegetation change and net primary productivity along the IGBP Northeast China Transect, Environ. Earth Sci., 62, 1481-1490, 2011.

Zhou, G. S. and Wang, Y. H.: Global Ecology, China Meteorological Press, Beijing, China, 2003.

Zhou, L., Tucker, C., Kaufmann, R., Slayback, D., Shabanov, N., and Myneni, R.: Variations in northern vegetation activity inferred from satellite data of vegetation index during 1981 to 1999, J. Geophys. Res.-Atmos., 106, 20069-20083, 2001. 